\title{
Cervus canadensis and C. elaphus: North American subspecies and evaluation of clinal extremes
}

\author{
Christine SCHONEWALD
} Schonewald C. 1994. Cervus canadensis and C. elaphus: North American subspecies
and evaluation of clinal extremes. Acta theriol. 39: 431-452.

The distinctiveness of each extant North American subspecies of $C$. elaphus (Linnaeus, 1758) was tested using craniometric data. To provide a context for interpretation of these data, the distinctiveness of North American C. elaphus from Eurasian $C$. elaphus was reassessed from existing data and conclusions tested. Morphometric variations in size, shape, and sexual dimorphism of adult crania were analyzed using combined male-female and independent male and female principal component analyses. North American subspecies do not represent natural biogeographic variation as earlier presumed. Posterior classification error was highest for subspecies, but was lowest for a set of 6 Operational Taxonomic Units that recognized C. elaphus-Olympic, C. elaphus-northern California and Oregon, C. elaphus-eastern Washington, C. elaphus-Rocky mountain and Cascade mountain, C. elaphus-Saskatchewan and Manitoba, and C. elaphus-central California. Males and females differed in their sizes, shapes and affinities to other populations. Intracontinental differences in the kind and amount of sexual dimorphism reinforced the importance of measuring and contrasting male and female features in phylogeographic analyses. Use of existing nomenclature as a blind guide for comparative systematics and ecology and for conservation undermines the quality of research and conservation for C. elaphus in North America. Previous arguments for a single-species circumglobal cline do not take into account sexual dimorphism, behavior and reproduction. Major intercontinental differences do exist between clinal extremes in behavior, in cranial size and sexual dimorphism in addition to semilethal $F_{1}$ hybridization. All suggest $C$. elaphus and North American Cervus are different species. Whether the transition is smooth, whether stepped transitions occur, and whether "canadensis" correctly represents the species' distribution need verification.

U.S. National Biological Survey Cooperative Studies Unit, and the Division of Environmental Studies, Wickson Hall, University of California, Davis, CA. USA 95616-8576

Key words: Cervus canadensis, Cervus elaphus, morphometry, subspecies, craniometry, phylogeography, conservation

\section{Introduction}

The natural distribution of Cervus elaphus (Linnaeus, 1758) [or Cervus canadensis (Erxleben, 1777)] in North America once extended throughout vegetated portions of Canada and the United States. Now it is limited to mostly protected sites in the western states and provinces with constricted ranges caused by anthropogenic disturbance. While the largest populations occur in the Rocky mountains, neighboring Canadian provinces, and north Pacific states, in other 
populations are restricted to protected sites. This restriction to protected sites has implications for most vertebrate species' survival (Schonewald-Cox et al. 1983, Schonewald-Cox and Bayless 1986).

Presently, the extant populations of C. elaphus in North America are subdivided into four subspecies, roosevelti, nannodes, merriami and nelsoni, based on the earlier systematic descriptions by Merriam (1897, 1905), Nelson (1902), and Bailey (1935); regional genetic studies by Dratch $(1983,1986)$ and Dratch and Gyllensten (1985); evolutionary and behavioral study by Geist (1991); localized natural history (Houston 1982) and morphometric descriptions by McCullough (1969), Hutton (1972), Schonewald-Cox et al. (1985), and McCorquodale et al. (1989). McCullough (1969) provides the first semi-quantitative morphometric description of C. elaphus nannodes and compares it to a few C. e. roosevelti and C. e. nelsoni specimens; he concluded C.e. nannodes was more appropriate than C. nannodes (Merriam 1905). Very little quantitative work has been completed on the biogeography of North American wapiti subspecies. Distributions are speculative; maps depict range limits and isolations, each different from the other, based on recent and variably documented characters (mostly '1940s' to present). In their literature review, Bryant and Maser (1982) attempted to clarify historic distributions for seven North American subspecies [manitobensis, merriami (listed as extinct), nannodes, nelsoni, roosevelti, virginianus (extinct), canadensis (extinct and limits unclear; see also Guthrie 1966)]. The Alaskan and Yukon (Canada) distribution (extinct, and nomenclature unclear) is elaborated upon by Guthrie (1966). Despite this and other reviews, documentation of the distributions and taxonomic relationships between various $C$. elaphus $(=C$. canadensis) subspecies have never been satisfactorily resolved.

My purpose was to test major assumptions on taxonomic relationships by using reproducible measurements from specimens in collections. The first assumption tested is that, phenotypic variation of C. elaphus in North America best matches the four extant subspecies (Table 1). The current taxonomy is assumed to be representative of natural diversity by scientists, managers, and legislators, sometimes creating controversy in protection (O'Brien and Mayr 1991). These subspecies designations are currently used by these professionals as the bases for measuring variation, conducting comparative studies, making conservation decisions and legislating protection or cull. If one were to proceed from the assumption that currently accepted subspecies represent real entities but, in fact, they do not, one risks (1) biasing ecological studies dependent on the species' systematics and (2) jeopardizing intraspecific biological diversity in legislation, conservation and management. The first part of this study is designed to measure phenotypic variability in wapiti using morphometry, the object being to test the congruence of geographic variation and current subspecific designations. This portion of the study examines size and shape features of the cranium; it examines variations in cranial sexual dimorphism and looks for effects of scale (order of magnitude of differences). A second assumption receives precursory testing to 
Table 1. Museum sources of 540 cranial specimens (a) and taxonomic and biogeographic groups (b) used for morphometric analysis of wapiti crania.

(a) Museum sources and numbers of specimens. Collections were not geographically restricted.

American Museum of Natural History, New York, NY 61

Museum of Vertebrate Zoology, Berkeley, CA 73

California Academy of Sciences, San Francisco, CA

Field Museum of Natural History, Chicago, IL 12

Unspecified ownership 22

Humboldt State College, Arcata, CA 69

Los Angeles County Museum, LA, CA 7

National Museum of Ottawa, Ontario 52

Pt. Reyes National Seashore, CA 3

$\begin{array}{lr}\text { National Museum of Natural History, Washington, D.C. } & 168 \\ \text { British Columbia Provincial Museum, Victoria, BC } & 18\end{array}$

Burke Museum, University of Washington, Seattle, WA 12

University of Washington Wildlife Department, Seattle, WA 10

(b) Categories North American subspecies/operational taxonomic units (OTU's). ${ }^{1}$

Subspecies (1) C.e.nelsoni Rocky mountain or Nelson's wapiti (some specimens of which were labeled C.e. canadensis),

(2) C. e. roosevelti (Pacific coast wapiti),

(3) C. e. nannodes Tule or dwarf wapiti,

(4) C. e. manitobensis (Manitoban wapiti).

Seven OTU's (1) RKYMT/CASC: Wyoming, including British Columbia [British Columbia was included because of its small sample size (though in subsequent projects this region should be tested for its local characteristics)], Banff, Montana, Upper Missouri river ( $n=66)$;

(2) SASK/MANIT: Saskatchewan and Manitoba, Canada $(n=17)$;

(3) EWASH: eastern Washington (male specimens from Pierce County, Mt. St. Helens in Skamania County, Gray S. Harbor County were lacking), Saskatchewan and Manitoba, Canada $(n=6)$;

(4) ALBT: Alberta, Canada (testing a possible separation of Alberta Province region from other RKYMT/CASC; $n=15$ );

(5) CCAL: central California, tule wapiti $(n=35)$;

(6) NCAL; northern California Roosevelt wapiti $(n=9)^{2}$;

(7) WWASH: Western Washington State, Olympic Peninsula counties $(n=23)$ to form 7-OTU's. For males, an EWASH sample was unattainable; only the remaining 6-OTU's were used.

Six OTU's (1) CCAL

(2) NCAL,

(3) WWASH,

(4) EWASH (no males) ${ }^{3}$,

(5) RKYMT/CASC,

(5) SASK/MANIT. ALBT and RKYMT/CASC are joined for purposes of analysis.

\footnotetext{
${ }^{1}$ Note that "elk" is as common an American term for Cervus elaphus deer as is "wapiti", perhaps more common even. The North American elk is not to be confused with European elk (Alces); therefore the "wapiti" term is used throughout, despite its sounding awkward in places.

${ }^{2}$ Our group made numerous attempts, wrote all agencies and universities (and state museums) to obtain Oregon crania, but none were kept for measure or other documentation, despite local hunting. Recently, Dratch (pers. com. 1993) reported that Oregon coastal wapiti are now restored (wapiti brought from other localities) and would not likely be of the same temporal sample as I have presently. The entire data set predates most management activities.

${ }^{3}$ The lack of male sample for eastern Washington EWASH (mentioned in the paper) was due to hunters keeping male heads. New animals result from translocations after early eradication of native stock.
} 
provide a context for interpretation of North American data. Lowe and Gardiner's $(1974,1989)$ interpretation that $C$. elaphus phenotypes represent one species implies the transition from North America to Europe constitutes a smooth cline, in which populations change gradually and demonstrate no significant divergence. Specimens are examined for their (1) allometric and pedomorphic characteristics, and (2) whether inter- and intracontinental variations are at the same scale. If one assumes that current taxonomy correctly represents the degree of evolution and conspecificity represented by "C. elaphus", but it does not actually do so (1) one risks biasing both intra- and intercontinental interpretations of $C$. elaphus biology, (2) the use of classifications risks obscuring differences in both anatomical and ecological characteristics, including recent adaptations (such as convergences), and (3) one risks missappropriating conservation efforts.

\section{Methods}

Morphometry of the cranium was selected for this study because (1) it has been the predominant measure of diversity for international comparative studies of C. elaphus, (2) it complements observations of behavior and tissue and blood electrophoresis, (3) its anatomy (excluding antlers and antler base) is less modified by environment in adulthood than other features such as coat pattern, color and texture (used in natural history accounts, such as Dolan 1988), body weight, and antler development, and (4) crania are easily preserved for future study. Females are more available than males. Female crania require less museum space, and are donated more often because hunters favor male crania and keep them as trophies, but we measured both males and females to reduce bias. In this study, principally U.S. and Canadian crania were measured using standard as well as large anthropometric calipers. All available specimens from Europe and Asia were measured. (No specimens were found from North Africa, Atlas mountains). Localities and sample sizes of specimens measured are listed in Table 2.

Because all subspecies other than C. e. nelsoni were under-represented in collections, most efforts were directed at equalizing biogeographic representation while simultaneously increasing sample size. There is a need for other, smaller-scaled and locally-detailed analyses of Nelson's wapiti for which there is an excess of specimens relative to other groups.

Table 2. List of specimens by locality. When two or more subspecies may occur within a state (U.S.A.) or province (Canada), the sample sizes are listed by either county or specific collection site. Further details can be obtained from the author.

Canada: Riding Mt. NP, Manitoba (16); Vancouver Island, B.C. (10); British Columbia (5); Banff, Alberta (17); Wapiti Island, Alberta (8); Waterton Park, Alberta (3); and Prince Albert NP, Saskatchewan (2).

U.S.A.: Olympic Penn., WA (22); Wahkiakum Co., WA (3); Lewis Co., WA (4); Pierce Co., WA (2); Mt. St. Helens, Skamania Co., WA (10); Grays Harbor Co., WA (1); Eastern Washington (2); Prairie Creek, Redwood National Park, CA (17); Buttonwillow - Tupman, CA (28); Owens Valley, CA (13); Cache Creek, Colusa Co., CA (4); Point Reyes NP, CA (2); San Mateo Co., CA (1); Monterey Co., CA (1); Colorado (7); Wyoming (37); Montana (11); N. Dakota (12); Nebraska (4); Virginia (10); Oklahoma (1); Upper Missouri River (3); Arizona (6); New York (2).

Eurasia: Spain (2); Norway (4); Scotland (2); Germany (8); Austria (1); Sardina (1); Iran (2); Turkestan (4); Kashmir (4); Kansu, China (5); Shansi, China (5); Manchuria Kirin, China (1); Amurland Mukhen and Alchi, [Chita Amur] China (1); New Zealand (domestic C. e. scotticus $\times$ nelsoni hybrids) (19). 
Out of 540 specimens examined and measured, 250 adult North American and 24 adult Eurasian crania were selected for analysis using SAS (SAS Inst. 1988; Table 1 for list of museums); the remainder were too young for this analysis, badly damaged, or of uncertain origin. Adults were conservatively judged to be individuals with full $\mathrm{M}^{3}$ and $\mathrm{M}_{3}$ eruptions (Bubenik 1982). While this might have missed some reproductive individuals, it probably did not include juveniles and distort the analysis. It was assumed that there could be effects of continued adult growth. Based on the hypothesis, patterns of pedomorhism should vary consistently within subspecies. Considerable variation in tooth-wear was observed in all populations, and the analysis was monitored for the effect of age. All specimens included in the analysis were from known localities, and about half predated 1920.

Thirty-six cranial characters were measured, but only 16 were selected for this analysis; this was done to maximize the comparative value of these data to other studies (Ahlen 1965, Lowe and Gardiner 1974, 1989, and Schonewald-Cox et al. 1985). The 16 characters that were analyzed are listed in Table 5 and illustrated in Schonewald-Cox et al. (1985). ${ }^{1}$

\section{Intracontinental analysis}

Principal components analysis (PCA), and step-wise, canonical discriminant analyses of log-transformed data were used to test relationships between subspecies and Operational Taxonomic Units (OTU's). The estimation of OTU's was based on plotting the first $3 \mathrm{PCs}$. Clustering was tested with the use of standardized stepwise canonical discriminant analysis and examination of posterior classification error probabilities for all OTU's. Alternatively to subspecies, 7- and 6-OTU's were used (Table 1).

Males and females were examined together and separately. Their sexually dimorphic traits were tested with independent Student's $t$-tests to substantiate how well my choice of OTU's identified homogeneity within subspecies, within OTU's, heterogeneity between subspecies, and between OTU's.

No a priori assumptions were made on (1) taxonomic relationships, (2) uniformity of dimorphism, or (3) that females were the only significant sex to analyze among specimens examined. Statistical assumptions and procedures followed methods described in detail in Schonewald-Cox et al. (1985).

\section{Intercontinental analysis: a preliminary evaluation}

Utilizing the same methods as in the North American analysis, the OTU separations were tested further by comparing the scale at which differences are apparent between continents and OTU's. The shortage of Asian data makes this assessment insufficient to be conclusive. Yet specimens measured here included old specimens predating the revolutions of eastern China and provide insight that may be helpful to subsequent analyses as well as this one. Principal Components analysis was used on log transformed data of the 16 variables for Eurasian and North American samples. Males and females were analyzed separately. Independent Student's $t$-tests were used to test whether cranial differences were statistically significant between Eurasian and North American C. elaphus. A statistically significant separation would be a level of difference in which (1) prominent characters differ between continents, (2) sexually dimorphic characters, not only degree of dimorphism, differ between continents, and (3) the scale of intercontinental differences exceeds that of intracontinental ones. Measurements collected by Ahlen $(1965)$ and Lowe and Gardiner $(1974,1989)$ were used for comparative purposes.

\footnotetext{
${ }^{1}$ During professional consultation with the eastern and southwestern park and forest managers the author became aware of additional information concerning C.e. merriami and C. e. canadensis. The validity appears doubtful for at least two subspecies C.e. canadensis and C.e. merriami. Most central and eastern specimens of $C$. e. canadensis were collected from populations derived from restorations using $C$. e. nelsoni introduced to replace extirpated C. e. virginianus. In the south western states $C$. e. nelsoni is introduced to replace extinct indigenous forms thought to be C. e. merriami. The author also suspects C. e. merriami were 3 individuals displaced from the North by human colonization east of the Rocky mountains; being plains animals, they most likely to have dispersed south along the western Missouri river banks. Based on (1) cranial characters, and (2) lack of archeological evidence of a resident population in the C.e. merriami biogeographic range.
} 


\section{Results}

\section{Intracontinental analysis}

Subspecies

Before proceeding, it is worth noting that wapiti in North America generally decrease in cranial size, moving from north to south; They are largest in the extreme Pacific northwest and upper Missouri. In this data set, size changes with both latitude (decreases moving south) and longitude (increases moving from western Europe to North America, with some irregularities in North America).
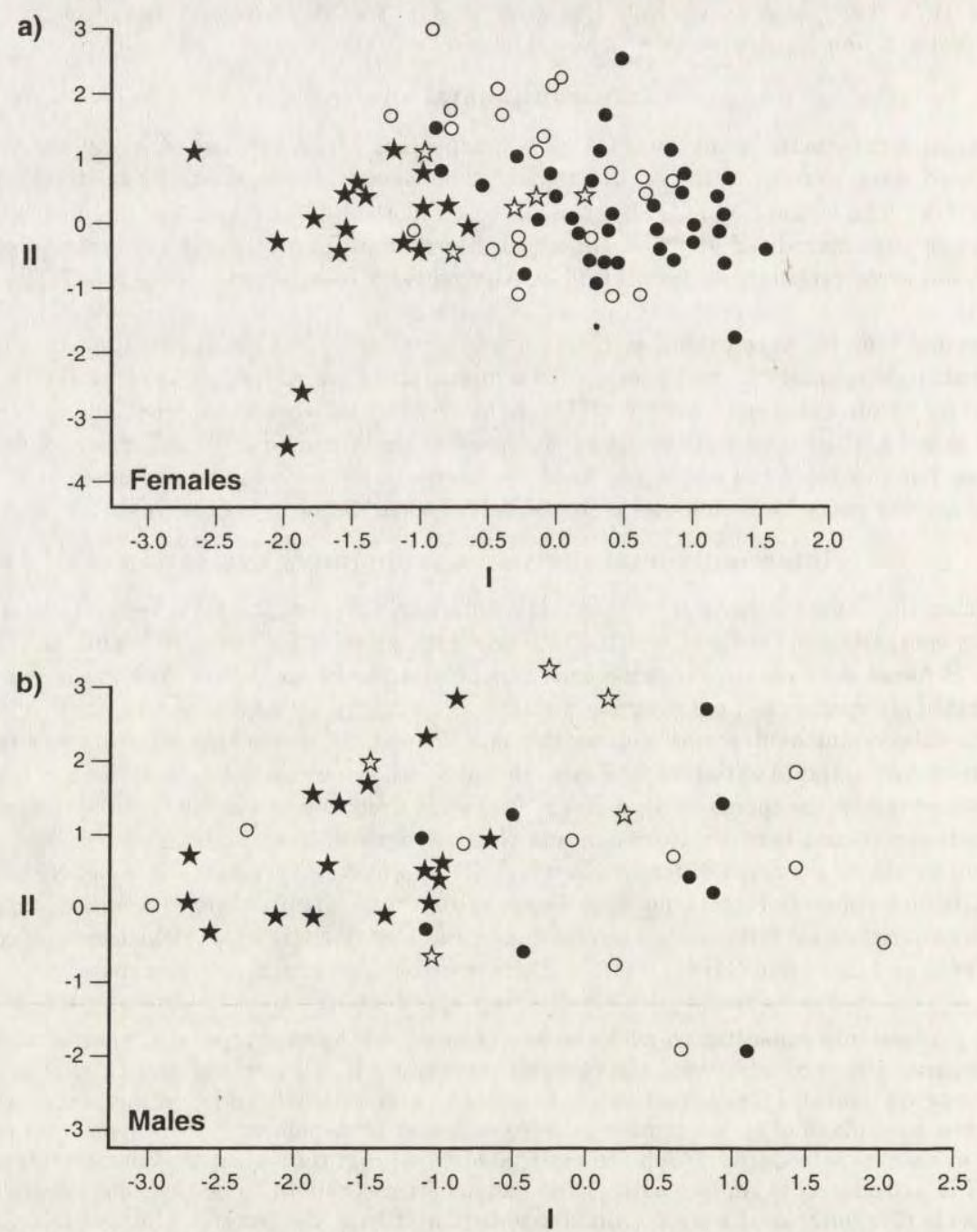

Fig. 1. PC analysis (axes I and II) for North American subspecies: (a) females, (b) males. Axis is predominantly an indicator for cranial length, and axis II for shape. Subspecies: $\star-C$. e. nannodes,

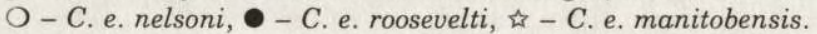


The distinction between North American subspecies was difficult to make in the combined male-female PCA. This resulted from a difference in degree of sexual dimorphism exhibited by North American populations; there was also overlap in phenotypic expressions between males and females among subspecies that made separation of subspecies difficult. C.e. nannodes $(n=35)$ skulls were only partly distinguishable from other skulls. Crania of C. e. roosevelti $(n=46)$, C. e. nelsoni $(n=33)$, and C. e. manitobensis $(n=11)$ were not separable from each other based on PC axes I and II. It was only on comparison of PC axes 3 and 1 that C.e. nannodes became evident, with $77 \%$ that did not overlap. Contrary to what might be expected, there was little useful information obtained from the analysis of subspecies using combined sexes.

The lack of separation was tested further with separate analyses for males and females. In PC analysis of only female characters (Fig. 1a), C. e. nannodes values overlapped $33 \%$ with those of C.e. nelsoni. In PC analysis of male characters (Fig. 1b) C. e. nannodes were indistinguishable from C. e. nelsoni on the first $2 \mathrm{PC}$ axes. The ability to distinguish C. e. nannodes from C. e. nelsoni increased when PC3 and 1 were compared. In comparing the first two canonical discriminant variates for females, C. e. roosevelti and C. e. nelsoni overlapped completely. Only C. e. nannodes and C.e. manitobensis were clearly distinguishable, but note the C.e. manitobensis sample was small $(n=5)$ and requires further testing. Pair-wise squared distances between group centroids used to determine the distances between subspecies for both males and females are listed in Table 3a. There was still too much overlap between subspecies to make accurate distinctions.

These results were confirmed in a test of posterior probability of classification, two of 23 C. e. nelsoni were misclassified as C. e. manitobensis, and five were misclassified as C. e. roosevelti. Seven out of 37 C. e. roosevelti were misclassified as C.e. nelsoni. The average error rate for females of all subspecies combined was $12.3 \%$; for C. e. roosevelti it was $18.9 \%$, and for C. e. nelsoni it was $30.4 \%$. For males, two C. e. roosevelti were misclassified: one as C.e. manitobensis, and the other as C.e. nelsoni. The expected average error rate was $5.6 \%$; the error rate for C. e. roosevelti was $22 \%$, and for C. e. nelsoni was $5.6 \%$. There was no error for C. e. manitobensis and C. e. nannodes (two latitudinal extremes).

Neither male nor female data (or combination) support the hypothesis that cranial phenotypes separate naturally into subspecies categories. How then do they separate?

\section{Seven OTU's}

There were two obvious interpretations: first, there are no significant differences between North American populations or, second, there are differences but they are not those delineated by subspecies. The second possibility was tested using operational taxonomic units (OTU's) derived from separation of data in discriminant analysis. Seven OTU's were identified with ranges that did not overlap, but which constituted the full North American distribution. Pacific 


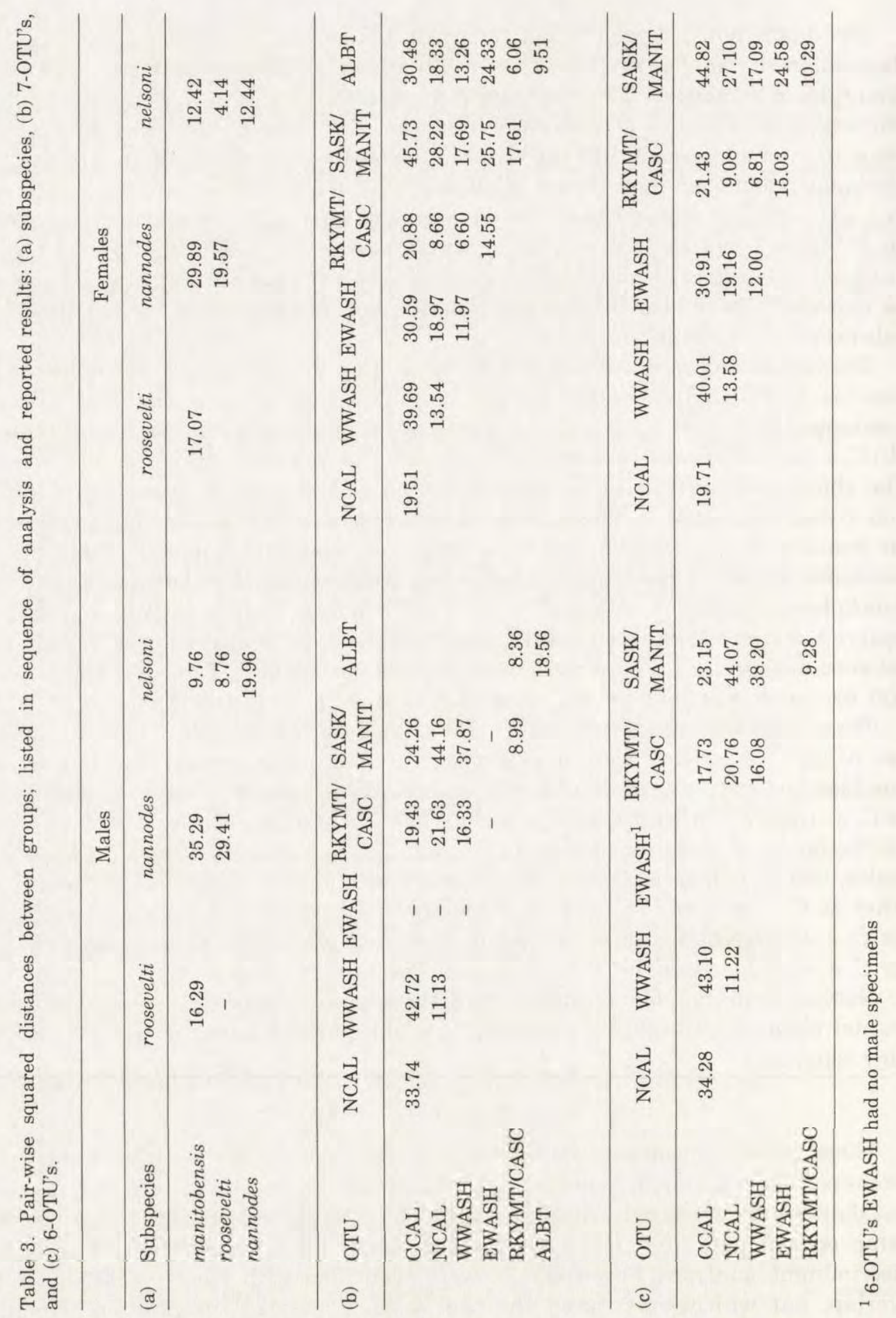


populations were first separated into 3 natural OTU's based on Schonewald-Cox et al. (1985). Use of these OTU's in addition to EWASH, RKYMT/CASC, ALBT, and SASK/MANIT OTU's was a testable alternative for how phenotypic diversity was distributed. Separating the Alberta population from the U.S. Rocky Mountain populations was justified further by contrasting $\mathrm{PC} 1$ and $\mathrm{PC} 2$ in the subspecies analysis. If valid, the use of OTU's (described in Table 1) should reduce error in posterior probabilities of classification and reduce misclassification of specimens later.

In the analysis, female OTU's were distinguishable but did not show clear separations between ALBT and SASK/MANIT. Despite the unclear separations, the posterior probabilities of membership for the 7-OTU's had a decreased average error rate from use of subspecies. The use of 7-OTU's was already more successful than subspecific taxonomy for characterizing the geographic craniometric diversity.

Relative relationships between 7-OTU groups differed substantially between males and females using pair-wise squared distances (Table $3 \mathrm{~b}$ ), suggesting the possibility OTU's differed in types of dimorphic characters. The most distinguished groups for females were CCAL and SASK/MANIT $(n=12)$ followed by CCAL and WWASH $(n=19)$. The most distinguishable groups for males were NCAL $(n=3)$ and SASK/MANIT $(n=5)$ followed by CCAL and WWASH $(n=4)$. For females, the groups least distinguishable from CCAL $(n=8)$, were NCAL $(n=6)$ and RKYMT/CASC ( $n=38)$. For males, the group least distinguishable from CCAL ( $n$ $=17$ ), was ALBT $(n=7)$ followed by RKYMT/CASC $(n=28)$. Evidently, while some distinctions were clearer with 7-OTU's than with subspecies, the new OTU separations over-extended sample size limitations, at least. Therefore, fewer OTU's were necessary.

\section{Six OTU's}

The ALBT OTU separation from surrounding populations was the least justifiable to keep, based on posterior probability of classification, sample sizes and likeness. Thus, the OTU's were reduced to six (five for males with lack of male EWASH specimens). Relative relationships between centroids of 6-OTU groups differed for males and females (Fig. 2). OTU's were distinctive. Results of the pair-wise squared distances (Table 3c) suggested that, in distinction to what was inferred from presumed taxonomic affinities, NCAL females are closer to RKYMT/CASC than to WWASH (Fig. 3a). However NCAL males are closest anatomically to WWASH, in contrast to females (Fig. 3b). CCAL is closest to NCAL for females, and CCAL is closest to RKYMT/CASC for males. For females, CCAL and SASK/MANIT were the most separate pair of OTU's followed by CCAL and WWASH. For males, NCAL and SASK/MANIT were the most separate pair, followed by CCAL and WWASH.

Eight measurements that contributed most to the separation of the 6-OTU's based on the absolute value of the summed first two standardized canonical 
a)

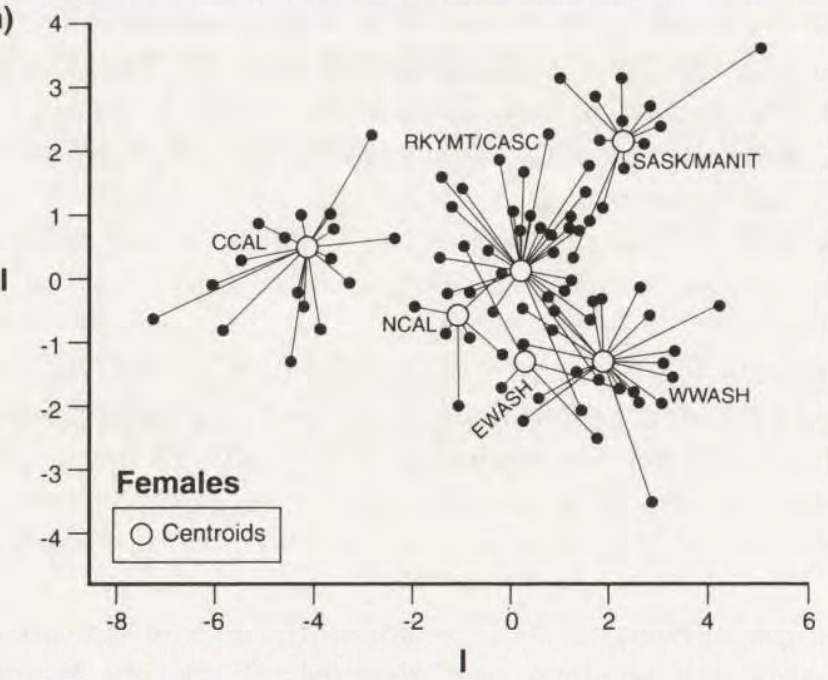

b)

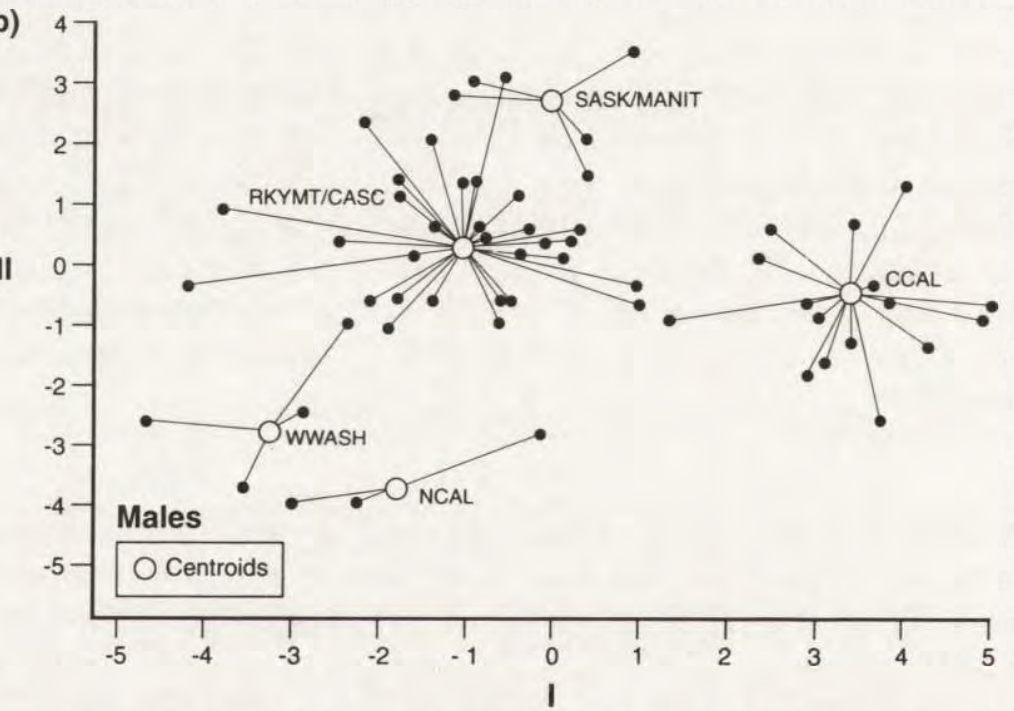

Fig. 2. Discriminant analysis for 6-OTU's: EWASH (females only), RKYMT/CASC, SASK/MANIT, WWASH, CCAL, and NCAL. (a) females, (b) males. Samples appear reduced due to overlapping points.

variates (Table 4) for males were: prosthion-alveolar length (3.08), condylobasal length (2.64), premaxillary length (1.88), palatal depth (1.62), frontal breadth (1.59), condylar breadth (1.56), maxillae width (1.51), and nose depth II (1.50). For females separation of OTU's was based primarily on palatal length (2.09), condylar breadth (1.39), basilar length (1.15), nasal length (1.07), prosthion-alveolar length (1.03), and nose depth I (1.03), interorbital width (0.91), braincase breadth (0.85), and palatal depth (0.84). 

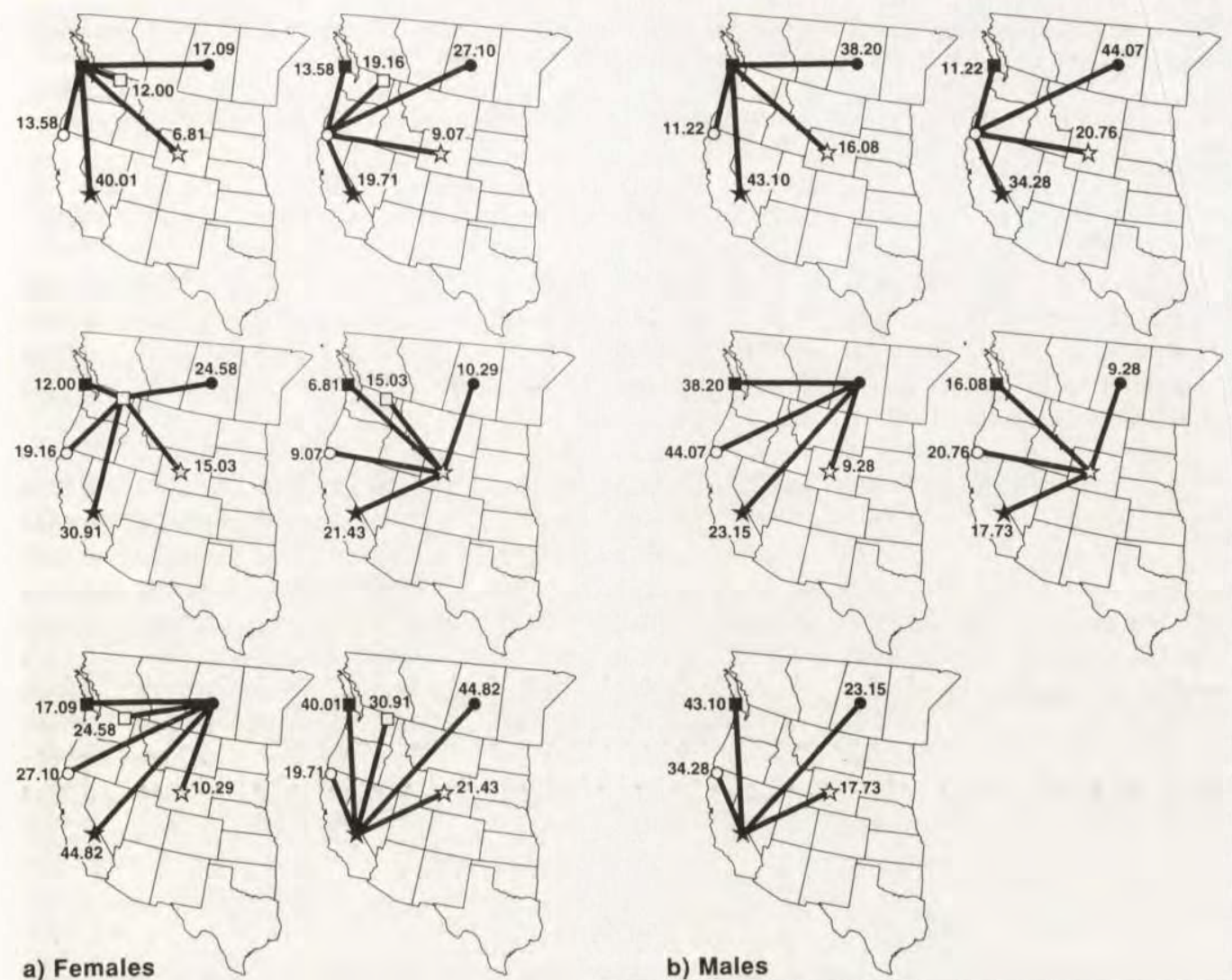

Fig. 3. Maps of western U.S.A. with pair-wise squared distances between each of 6-OTU's for females (a) and males (b) (no EWASH for males) designed to be illustrative of distance between OTU's. These are different than would be intuited based on subspecific classification. Bars do not suggest migration or dispersal routes or extents of distributions. They are there to exclusively connect points. OTU's are: 口-EWASH, מ - RKYMT/CASC, - SASK/MANIT, $\boldsymbol{-}$ - WWASH, $\star$ - CCAL, O - NCAL.

Misclassification rates for 6-OTU's were $10.2 \%$ for females and $1.9 \%$ for males. Most errors were associated with RKYMT/CASC (9.7\% males, $20.5 \%$ females) which needs further study. These results were improved over those based on taxonomic comparisons of subspecies or use of 7-OTU's. The three RKYMT/CASC misclassifications were from CCAL (1), WWASH (1), and SASK/MANIT (1). There was no misclassification for OTU's other than RKYMT/CASC for males (CCAL, NCAL, WWASH, SASK/MANIT: no errors). Error rates for females were 0\% (CCAL, EWASH), 16.7\% (NCAL), 15.8\% (WWASH), and 8.3\% (SASK/MANIT). These were the best results so far, indicating that it was current classification that confused the analysis, and differences between populations exist. Six OTU's were determined to the most useful definition of North American phenotypes based on this survey coverage. 
Table 4. Canonical coefficients and standardized canonical coefficients for the 6-OTU North American populations, males and females are listed separately.

\begin{tabular}{|c|c|c|c|c|c|c|c|c|}
\hline \multirow[b]{2}{*}{ Measurement } & \multicolumn{4}{|c|}{ Males } & \multicolumn{4}{|c|}{ Females } \\
\hline & $\begin{array}{l}\text { RAW } \\
\text { CAN1 }\end{array}$ & $\begin{array}{l}\text { RAW } \\
\text { CAN2 }\end{array}$ & $\begin{array}{c}\text { STAND. } \\
\text { CAN1 }\end{array}$ & $\begin{array}{l}\text { STAND. } \\
\text { CAN2 }\end{array}$ & $\begin{array}{l}\text { RAW } \\
\text { CAN1 }\end{array}$ & $\begin{array}{l}\text { RAW } \\
\text { CAN2 }\end{array}$ & $\begin{array}{c}\text { STAND. } \\
\text { CAN1 }\end{array}$ & $\begin{array}{c}\text { STAND. } \\
\text { CAN2 }\end{array}$ \\
\hline Condylobasal length & -26.5838 & -84.8569 & -0.6308 & -2.0134 & 87.5479 & -26.6067 & 1.8182 & -0.5526 \\
\hline Basilar length & -9.3366 & 11.0971 & -0.2313 & 0.2749 & -47.0312 & -7.2582 & -1.0023 & -0.1547 \\
\hline Rostrum length & -6.0810 & -36.8013 & -0.1488 & -0.9007 & -7.8538 & -2.3945 & -0.1871 & -0.0571 \\
\hline Palatal length & 2.2035 & 24.1441 & 0.0683 & 0.7482 & 58.7124 & 34.8529 & 1.3103 & 0.7778 \\
\hline \multicolumn{9}{|l|}{ Prosthion-Alveolar } \\
\hline length & -18.6625 & 73.9908 & -0.6199 & 2.4579 & -6.2669 & 28.1343 & -0.1875 & 0.8416 \\
\hline Premaxillary length & 38.0162 & 32.2057 & 1.0208 & 0.8648 & 12.9119 & 14.7608 & 0.2873 & 0.2384 \\
\hline Nasal length & -2.4868 & -35.2315 & -0.0662 & -0.9379 & -16.7784 & -17.8902 & -0.5171 & -0.5514 \\
\hline Nasal Breadth & -2.0593 & 1.0528 & -0.0959 & 0.0490 & 6.2144 & -3.1641 & 0.2739 & -0.1395 \\
\hline Maxillae width & -7.3493 & -33.4646 & -0.2727 & -1.2416 & -14.6886 & -16.8839 & -0.3672 & -0.4221 \\
\hline Frontal breadth & 30.7632 & 39.2593 & 0.7010 & 0.8946 & -11.4194 & -5.1034 & -0.2092 & -0.0935 \\
\hline Interorbital width & -7.9695 & -32.1071 & -0.2076 & -0.8365 & -4.1274 & -36.4137 & -0.0928 & -0.8184 \\
\hline Braincase breadth & -39.0400 & -20.7674 & -0.82 .74 & -0.4402 & 26.8612 & 17.8833 & 0.5077 & 0.3380 \\
\hline Condylar breadth & -48.8723 & 1.3234 & -1.5174 & 0.0411 & 31.7471 & -20.0610 & 0.8547 & -0.5401 \\
\hline Nose depth I & 0.6743 & -3.8631 & 0.0267 & -0.1527 & -8.4081 & 25.0556 & -0.2579 & 0.7687 \\
\hline Nose depth II & 4.3534 & 47.4035 & 0.1264 & 1.3766 & -6.0226 & -20.4116 & -0.1656 & -0.5611 \\
\hline Palatal depth & 38.5886 & 24.6319 & 0.9918 & 0.6331 & 0.6619 & 37.5382 & 0.0146 & 0.8297 \\
\hline
\end{tabular}

\section{Four OTU's}

In an attempt to classify using only 4-OTU's with all the same analyses, eliminating EWASH, increased the posterior probability of error, so nothing was gained from reduction. For represented localities, the 6-OTU's comprise the optimal subdivisions of biogeographic regions for North America.

\section{Sexual dimorphism}

Subspecies. When all subspecies were pooled, the wapiti crania exhibited significant sexual dimorphism $(p<0.01)$. Perhaps more significantly, the subspecies varied in the kind and degree of their sexual dimorphism; only C. e. nannodes and C.e. roosevelti were dimorphic for all measures. The other two subspecies differed in how they were dimorphic: C.e. manitobensis was dimorphic for most (13) measures but monomorphic for prosthion-alveolar length, nasal length, and nasal breadth; C. e. nelsoni was dimorphic for most (14) measures but monomorphic for palatal length and prosthion-alveolar length. Characters which helped separate sexes for subspecies and OTU groups in stepwise discriminant analysis included condylobasal length ( $F$ value was greater for females than males), maxillary width ( $F$ value was greater for females than males), prosthion-alveolar length ( $F$ value was greater for females than males), condylar breadth ( $F$ value was greater for males than females), premaxillary length ( $F$ value was greater for 
males than females), nasal depth I (important only in females), and nasal length (important only in females). Still, considerable dimorphism was obscured with the use of only subspecies classification.

6-OTU's. Table 5 (details in Table 7) shows how sexual dimorphism differed between 5-OTU's comparison not possible for the EWASH OTU (due to lack of male crania), and Figure 2 illustrates this in how population data were distributed about the canonical axes I and II. Size factors seem predominant along axis I, and shape along II. The relative positions of OTU's differs between males and females.

As was illustrated by pair-wise squared distances, a significant distinguishing feature among OTU's was sexual dimorphism (Fig. 3, Table 3c). A single study depending on the morphometry of a single sex, whether males or females, could be misleading. If the 6-OTU's were natural phenotypic categories, one might expect the sexual dimorphism to differ similarly, or only in degree, between the 6-OTU's. The separation should be clearer between the 6-OTU's than between the subspecies, 7-, or 4- OTU's. Student $t$-tests for sexual dimorphism were positive for 5-OTU's (summary in Table 5, details in Table 7). The identity of characters that were dimorphic differed between OTU's. Individuals from CCAL and RKYMT/CASC were sexually dimorphic for all characters. NCAL was most similar to these differing only in the single non-dimorphic character, palatal length. SASK/MANIT was sexually dimorphic for all but basilar length, rostrum length, palatal length, prosthion-al-

Table 5. List of cranial measurements and comparison of sexual dimorphism of Cervus elaphus in North America for 6-OTU's (EWASH has no male specimens) and Eurasia. Significance of differences between males and females was marked by: *** for $p<0.0001,{ }^{* *}$ for $p<0.05$, * when dimorphism exists but statistically insignificant, "-" when no dimorphism was found. Eurasian (E) and North American $(\mathrm{N})$ categories serve to ilustrate that significant sexual dimorphism can be percieved despite differences in the kinds of dimorphism that exist between OTU's. N+E are all samples, Eurasia and North America pooled.

\begin{tabular}{|c|c|c|c|c|c|c|c|c|}
\hline $\mathrm{L}=$ Measure & CCAL & NCAL & WWASH & $\begin{array}{c}\text { RKYMT/ } \\
\text { CASC }\end{array}$ & $\begin{array}{l}\text { SASC/ } \\
\text { MANIT }\end{array}$ & $\mathrm{N}$ & $\mathrm{E}$ & $\mathrm{N}+\mathrm{E}$ \\
\hline $1=$ Condylobasal length & $* * *$ & *** & * & $* * *$ & $*$ & $* * *$ & - & $* * *$ \\
\hline $2=$ Basilar length & $* * *$ & $* * *$ & $* *$ & $* * *$ & - & $* * *$ & - & *** \\
\hline $3=$ Rostrum length & $* * *$ & $* * *$ & $*$ & $* * *$ & - & $* * *$ & $*$ & $* * *$ \\
\hline $4=$ Palatal length & * & - & - & $* * *$ & - & $*$ & - & $* * *$ \\
\hline $5=$ Prosthion-alveolar length & $* * *$ & $* * *$ & - & $* * *$ & - & $* *$ & $*$ & *** \\
\hline $6=$ Premaxillary length & $* * *$ & $* *$ & - & $* * *$ & - & * & * & *** \\
\hline $7=$ Nasal length & * & ** & * & $* * *$ & - & $* * *$ & - & $* * *$ \\
\hline $8=$ Nasal breadth & $* * *$ & $* *$ & - & $* * *$ & $* * *$ & *** & - & $* * *$ \\
\hline $9=$ Maxillae width & $* * *$ & $*$ & - & $* * *$ & $* * *$ & $* * *$ & $* *$ & *** \\
\hline $10=$ Frontal breadth & $* * *$ & * & * & $* * *$ & $* *$ & $* * *$ & $* * *$ & $* * *$ \\
\hline $11=$ Interorbital width & $* * *$ & $* *$ & - & $* * *$ & $* * *$ & $* * *$ & $* *$ & $* * *$ \\
\hline $12=$ Braincase breadth & $* * *$ & * & $*$ & $* * *$ & $* * *$ & $* * *$ & $*$ & *** \\
\hline $13=$ Condylar breadth & $* * *$ & $* *$ & $* * *$ & $* * *$ & $* * *$ & $* * *$ & $* *$ & *** \\
\hline $14=$ Nose depth I & $* * *$ & $* * *$ & $*$ & $* * *$ & $* * *$ & $* * *$ & - & $* * *$ \\
\hline $15=$ Nose depth II & $* * *$ & $* *$ & ** & $* * *$ & $* * *$ & $* * *$ & ** & $* * *$ \\
\hline $16=$ Palatal depth & $* * *$ & $*$ & $* *$ & $* * *$ & *** & $* * *$ & $* *$ & $* * *$ \\
\hline
\end{tabular}




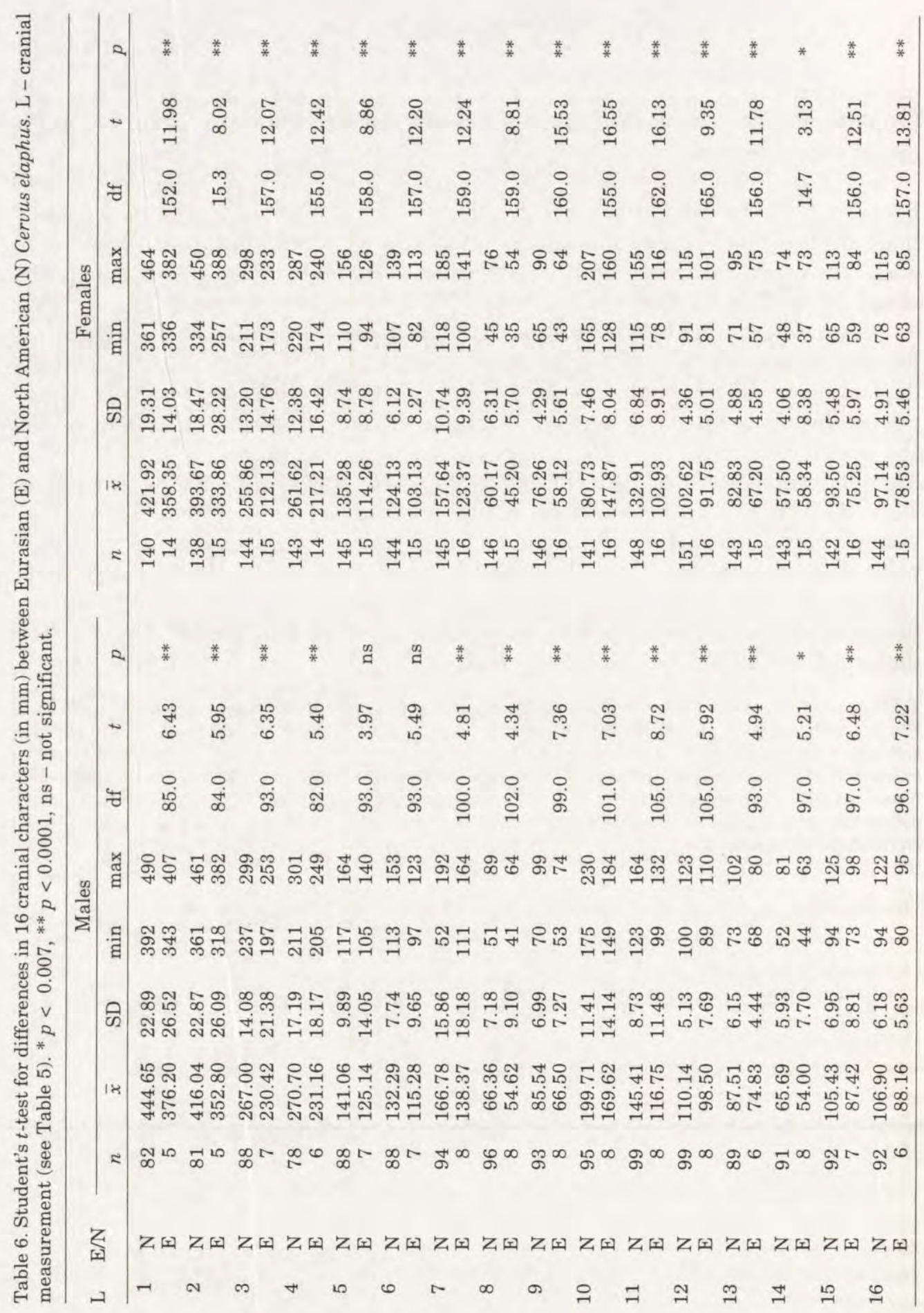


veolar length, premaxillary length, and nasal length. SASK/MANIT and WWASH were the least dimorphic of all OTU's. Note the pronounced differences between WWASH and NCAL or WWASH and RKYMT. WWASH were sexually dimorphic for only basilar length, frontal breadth, braincase breadth, condylar breadth, nose depth II, and palatal depth. Although CCAL, NCAL and RKYMT/CASC were all similarly dimorphic, WWASH, typically considered the same subspecies as NCAL, differed dramatically in its cranial dimorphism from NCAL, more so than CCAL differs from NCAL or RKYMT. This added further support to the value of using an alternative, interpretation to the current subspecific designations. In this analysis of sexual dimorphism, three principal groups are evident: WWASH, SASK/MANIT and "Others". This is one more way in which OTU's may differ from each other.

\section{Intercontinental analysis}

Examined as two groups, Eurasian and North American specimens were both statistically different for all 16 measurements $(p<0.05)$. The PCA for all females measured showed a clear separation of Eurasian and North American characters. Characters with heaviest loadings for female intercontinental PC1 were condylobasal length (0.96), basilar length (0.93), rostrum length (0.93), frontal breadth (0.92), and interorbital width (0.92); and for PC2 they were palatal length $(0.26)$, prosthion alveolar length ( 0.33$)$, and nasal breadth $(-0.60)$; for PC3 they are nasal length $(-0.31)$, and nose depth I (0.58). Length of the cranium is the dominating (although not the single) distinguishing feature between continents for females.

The intercontinental PC for males also showed separation between Eurasian and North American characters. Characters with heaviest loadings for males PC1 are for condylobasal length (0.96), basilar length (0.96), rostrum length (0.95), interorbital width (0.95), nasal length (0.92), and nose depth II (0.93). PC2 contrasts palatal length $(0.21)$ and premaxillary length $(0.22)$, with nasal breadth $(-0.51)$ and nose depth I $(0.28)$. Length of the cranium is one dominating feature distinguishing between continents for males, but not the only one; another is the difference in nasal shape.

In addition to overall size, a summary of PC analyses for both sexes suggests that the rostrum length, interorbital width, palatal depth, and nasal breadth measures were preliminarily valuable in determining whether specimens are either Eurasian or North American. How this holds with increased sample size and intracontinental variation for Asia, particularly, remains to be determined. Besides a presence of antlers in males, obviously, the frontal breadth and prosthion alveolar length were prominently sexually dimorphic for North American specimens while preliminarily assessed as monomorphic for Eurasian specimens. The premaxillary length was also useful in identifying North American origin in males. In addition, all other measures differed between continents for both sexes, except female nose depth I ( $p<0.001$; Table 6).

Taken as a single samples, each, North American males and females were dimorphic for all measurements except palatal length, which was a marginal case, 
Table 7. Sexual dimorphism in cranial measures, based on Student's $t$-tests. Results are supported by Student $t$-test of discriminant functions for the same groups. (a) OTU's NCAL, WWASH, RKYMT/CASC, SASK/MANIT, CCAL = G; (b) Global data base (Eurasia and North America combined), Eurasia, and North America. L - cranial measurements (see Table 5). If $p<0.05$ dimorphism is supported. ${ }^{1}$ SET 2 (without partial skulls).

(a)

\begin{tabular}{|c|c|c|c|c|c|c|c|c|c|c|}
\hline \multirow{2}{*}{$\mathrm{L}$} & \multicolumn{2}{|c|}{ NCAL } & \multicolumn{2}{|c|}{ WWASH } & \multicolumn{2}{|c|}{ RKYMT/CASC } & \multicolumn{2}{|c|}{ SASK/MANIT } & \multicolumn{2}{|c|}{ CCAL } \\
\hline & $F$ & $p$ & $F$ & $p$ & $F$ & $p$ & $F$ & $p$ & $F$ & $p$ \\
\hline 1 & .3022 & .0000 & .3680 & .0071 & .0051 & .0001 & .0333 & .0437 & .8926 & .0000 \\
\hline 2 & .5549 & .0003 & .0784 & .0014 & .1005 & .0000 & .0023 & .0646 & .5972 & .0000 \\
\hline 3 & .5156 & .0004 & .3175 & .0136 & .2213 & .0000 & .0115 & .1559 & .3065 & .0000 \\
\hline 4 & .3774 & .0745 & .0333 & .5235 & .0001 & .0001 & .0747 & .1175 & .0271 & .0134 \\
\hline 5 & .0709 & .0005 & .3684 & .3690 & .0698 & .0000 & .0381 & .1586 & .5045 & .0001 \\
\hline 6 & .3872 & .0011 & .7964 & .3392 & .0636 & .0000 & .0160 & .1594 & .3511 & .0000 \\
\hline 7 & .1212 & .0021 & .3075 & .0130 & .4403 & .0000 & .1028 & .1285 & .0003 & .0371 \\
\hline 8 & .2734 & .0030 & .0371 & .0664 & .1728 & .0000 & .5992 & .0005 & .8515 & .0000 \\
\hline 9 & .0052 & .0258 & .0000 & .1243 & .0105 & .0001 & .0272 & .0004 & .0290 & .0001 \\
\hline 10 & .0064 & .0058 & .0014 & .0417 & .0111 & .0001 & .0142 & .0013 & .8568 & .0000 \\
\hline 11 & .0777 & .0000 & .0176 & .1402 & .0149 & .0001 & .0062 & .0001 & .4190 & .0000 \\
\hline 12 & .0000 & .0091 & .6670 & .0105 & .0064 & .0001 & .1328 & .0005 & .1659 & .0000 \\
\hline 13 & .4331 & .0000 & .2796 & .0005 & .1184 & .0000 & .2818 & .0002 & .4521 & .0000 \\
\hline 14 & .6651 & .0000 & .3083 & .0150 & .0062 & .0001 & .0059 & .0208 & .0918 & .0000 \\
\hline 15 & .0114 & .0035 & .6518 & .0041 & .1351 & .0000 & .1482 & .0000 & .9474 & .0000 \\
\hline 16 & .0025 & .0168 & .1489 & .0006 & .1110 & .0000 & .2155 & .0002 & .3533 & .0000 \\
\hline
\end{tabular}

(b)

\begin{tabular}{|c|c|c|c|c|c|c|c|c|}
\hline & \multicolumn{2}{|c|}{ Global data base } & \multicolumn{2}{|c|}{ Eurasian } & \multicolumn{2}{|c|}{ Global data base ${ }^{1}$} & \multicolumn{2}{|c|}{ North America } \\
\hline & $F$ & $p$ & $F$ & $p$ & $F$ & $p$ & $F$ & $p$ \\
\hline 1 & .4294 & .0001 & .0709 & .0710 & .0792 & .0000 & .2593 & .0000 \\
\hline 2 & .7690 & .0001 & .9719 & .2032 & .0284 & .0001 & .1714 & .0000 \\
\hline 3 & .7616 & .0001 & 2381 & .0293 & .4924 & .0000 & .9286 & .0001 \\
\hline 4 & .4503 & .0018 & .7050 & .1085 & .0007 & .0001 & .0005 & .0347 \\
\hline 5 & .7487 & .0001 & .1385 & .0372 & .1923 & .0000 & .3610 & .0039 \\
\hline 6 & .4429 & .0001 & .5903 & 0063 & .0126 & .0001 & .1496 & .0000 \\
\hline 7 & .0288 & .0001 & 0303 & .0564 & .0000 & .0001 & .0000 & .0060 \\
\hline 8 & .4163 & .0001 & .1304 & .0059 & .1603 & .0000 & .0723 & .0000 \\
\hline 9 & .0357 & .0001 & .3806 & .0049 & .0000 & .0001 & .0000 & .0001 \\
\hline 10 & .4161 & .0001 & .0630 & .0001 & .0000 & .0001 & .0000 & .0001 \\
\hline 11 & .8505 & .0001 & 3883 & .0037 & .0074 & .0001 & .0564 & .0000 \\
\hline 12 & .2267 & .0001 & .1556 & .0164 & .0700 & .0000 & .6053 & .0000 \\
\hline 13 & .9114 & .0001 & 1.0000 & .0024 & .0141 & .0001 & .0385 & .0005 \\
\hline 14 & .0001 & .0001 & .8721 & .3602 & .0000 & .0001 & .0003 & .0001 \\
\hline 15 & .1990 & .0001 & .2080 & .0008 & .0114 & .0001 & .4519 & .0000 \\
\hline 16 & .3413 & .0001 & .8407 & .0018 & .0139 & .0001 & .2773 & .0000 \\
\hline
\end{tabular}


appearing monomorphic. The identity of sexually dimorphic features differs dramatically between Eurasia and North America; and requires additional testing. Results are summarized in Table 6 (details in Table 7).

\section{Discussion}

The results of this study are mostly consistent with those of other comparative studies utilizing morphometry, blood chemistry, external coat characters, and behavior; there is some argument with Lowe and Gardiner (1989). Patterns and rates of evolution are not measured (see Avise 1989) and therefore make interpretation difficult, especially as regards taxonomy, but significant and predictable differences exist within and between continents.

\section{North American intracontinental distribution}

Schonewald-Cox et al. (1985) compared cranial variation for U.S. Pacific coast populations, and concluded that cranial phenotypes separated differently than would be expected based on subspecies classification. Four resulting Operational Taxonomic Units OTU's were (with least posterior error probabilities): central California, northern California, Washington State, and (introduced) Vancouver Island. The authors also found that the type C.e. nannodes specimen (adult teeth not fully erupted) and the zoo specimens fell outside the expected morphological range for all C. e. nannodes. The author concluded that blind uses of current subspecific designations for coastal populations of wapiti was misleading in both research and conservation.

In a short term study of C. e. nannodes, Kucera (1991) detected a proportion of 0.053 polymorphism in tule wapiti in a sample of 24 individuals (based on liver and kidney tissue). He concluded the lower than "usual" variation in the tule wapiti was attributable to previous population bottlenecks. In the museum collections examined, there were several abnormal crania exhibiting agnathia (from a sex-linked recessive sublethal allele in cattle; not sex-linked in C.e. nannodes). The California history that has contributed to these bottlenecks includes: (a) the Spanish agricultural expansion during which cattle were introduced to tule wapiti habitats (from 1776), (b) the Gold Rush in California during which tule wapiti were hunted (from 1846), and (c) the subsequent subdivisions and inbreeding of populations as part of restoration efforts (Bureau of Land Management 1986). Cervus e. nannodes may be responding to accumulated effects of intense environmental selection (exaggerated xeric conditions, serial bottlenecks, sustained inbreeding, and restricted mobility). Therefore, it is worth making a precautionary note: If the size of C. e. Nannodes is entered into the comparison across the bearing straits, the transition may seem smooth and differences reduced; however, C. e. nannodes is likely to be secondarily small by convergence with old world C. elaphus (size is a major factor in the PCA analysis). 
Reductions in size have been induced by intense recent selection and diet (mentioned earlier). If C.e.nannodes is extracted from the analysis, the separation between continents is even clearer. This suggests the possible existence of a stepped transition in the cline across the bearing straits (hypothesis).

The use of OTU's facilitated the separation of localities by dramatically reducing posterior classification error probabilities by $2.1 \%$ for females and $3.5 \%$ for males (out of initial $12.3 \%$ for females and 5.6\% for males); this is with no prior assumptions made on the interrelations between existing taxa, or existing distributions. The use of 6-OTU's, instead of subspecies, for the 16 measurements improved the statistical accuracy in tests reclassifying individuals. These OTU's were (a) central California tule population (C.e. nannodes), (b) northern California Roosevelt population (C.e. roosevelti), (c) Olympic peninsula and Wahkiakum and Lewis County populations of Washington State $(C . e$. roosevelti), (d) eastern Washington state population (C. e. roosevelti; based on females only), (e) Rocky and Cascade mountain populations (C.e.nelsoni), and (f) Saskatchewan-Manitoba population (C. e. manitobensis). The eastern Washington, Rocky mountain and Cascade mountain OTU's need closer examination. Analysis of sexual dimorphism demonstrated significant differences of kind, not just degree, between northern California and western Washington (Olympic) OTU's, a dimorphism that differs from that of central California. The latter is equivalent to northern California and Rocky mountain/Cascade kinds of variation in dimorphism. Based on the measures of this study, the subspecies most in question and at risk of mismanagement is C. e. roosevelti (three varieties). Also unresolved is the status of C. e. nelsoni (two varieties, potentially, if ALBT is supported by further study).

Dratch's (1986) data support the interpretation of the uniqueness of the Olympic roosevelt population, and he suggests the transition in polymorphism frequencies is immediately south of the Olympic peninsula. C. elaphus-Olympic differs in size and shape from other $C$. e. roosevelti, and has unique sexually dimorphic cranial characters. Similar clarification is needed for the less well documented Eastern Washington and Alberta OTU's; their status and history remain unclear. Dratch (1986) found interesting biochemical differences in these regions that suggest possible introductions. Among the North American populations, C. e. nannodes, the two Roosevelt populations, C. e. nelsoni, C. e. manitobensis, and the eastern Washington wapiti need separate attention.

\section{Intercontinental distribution}

Lowe and Gardiner (1989) describe the distribution of C. elaphus as one cline based on the morphometry of Eurasian specimens and 11 North American specimens. They assume statistically that (1) subspecies are real, (2) change is continuous, circumglobally (smooth cline), and (3) only female cranial characters are significant. C. e. nannodes that would smooth the intercontinental rela- 
tionships due to its small size, can confound analyses because it is more likely that its size and shape are results of population bottlenecks and site selection for reserves, developing new convergent apomorphies (Mayr 1988); this is rather than their having retained characters homologeous to Eurasia.

Based on an electrophoretic analysis of 38 loci and 16 enzymes, Dratch (1983) found polymorphisms contrary to earlier studies such as Cameron and Vyse (1978) who analyzed only Yellowstone wapiti. Dratch found two North American polymorphic loci (MPI and PEP-2) that when tested on the same gels were not simultaneously polymorphic for C. elaphus in Scotland. The only polymorphism characteristic of all North American sites tested was MPI. IDH-2 was polymorphic at all sites except the Olympic peninsula, Washington; it was monomorphic there. SOD-1 was monomorphic at only Mt. St. Helens, Washington, and two of the four Idaho localities tested. For both PGM-1 and PEP-2, the sites West of the Cascade mountains showed variation, while those East did not show the variation. His results are consistent with earlier results of Baccus et al. (1983) for Montana. His study, which focused on C. e. scotticus and North American comparisons, covered a limited region including northern subspecies, C. e. roosevelti and the most western C.e. nelsoni. In Dratch's (1983) comparisons in which variation was tested collectively, he found that the "source of non-individual variation totaled $37.3 \%$. Nearly twice as much of this variation is due to differences between red deer and wapiti (24.6\%), than due to differences between populations within the two groups 12.7\%"; (Dratch 1983, pg. 81). This suggests a scaled (order of magnitude) difference in variation. His use of Nei's (1972) dendrogram of genetic distance demonstrated a scale of difference in the separation between Scotland and North America and the separations within continents. He mentions Baccus et al.'s (1983) comparison of Swedish and Montana C. elaphus produced similar and more pronounced differences. Recall that C.e. scotticus is an island form, and therefore may not be the appropriate "opposite extreme" (for use in the analysis of the biogeographic cline).

Still, in Dratch's (1986) and subsequent work in the artificial contact zone of New Zealand evidence exists for semi-lethal hybridization in clinal extremes. Although, $\mathrm{F}_{1}$ offspring do occur from hybridization of both clinal extremes $(C$. $e$. scotticus $\times$ nelsoni), it is only with aided $\mathrm{F}_{1}$ delivery during parturition that viable young are produced (Caughley 1971, Dratch 1983, 1986, Gyllensten et al. 1983). This reproductive barrier reinforces the interpretation of evolutionary separation of western-most Eurasian and North American distributions; it resembles the kind of reproductive isolation (or semi-isolation) associated with large biogeographic clinal extremes (discussed in Mayr et al. 1953). Secondly, the New Zealand crania measured in this study exhibited bimodal characteristics: beringean or elaphine, these results were consistent with those of Batcheler and McLennan (1977). Thirdly, the existence of differences in sexual dimorphism, subject to sexual selection, provides further evidence that other factors such as recognition and receptivity differences between mates likely exist. 


\section{Conclusions}

Significant differences in behavior including roar (noise) versus bugle (tending towards pure-tone) male vocalization, anatomical differences including size, shape and especially sexual dimorphism differences, and semi-lethal hybridization effects support the validity of C. elaphus (Linnaeus, 1758) and C. canadensis (Erxleben, 1777) rather than just C. elaphus (based on Mayr criteria 1988). These conclusions do not need to rely exclusively on the few craniometric results presented here, but are supported by them. Previous analyses of global distributions are geographically and sexually biased, rely only on craniometry, and could not provide defendable criteria for separation or union between new and old world forms.

One important question remains unresolved however. Even though clinal extremes show specific or neospecific differences, (Scottish Highlands red deer and North American wapiti), it is not clear where the separation takes place geographically between these extremes, if the transition is smooth or stepped. We need to determine if there is a location where one or several stepped transitions take place, and if steps exist whether they (it) are most obvious across the Bearing straits or most obvious within the Eurasian continent.

Within North America, phenotypic differences are clear, their conservation significance is clear, but their taxonomic significance is less clear. As has been demonstrated by Avise et al. (1990) for mallards and black ducks, the recent distributional changes in temperate fauna associated with the last few ice ages induced isolations, regional divergences and subsequent biogeographic expansions that are now evident in the phenotypic diversity of wapiti described here (see also Guthrie 1966 for Alaskan wapiti); these have been rapid changes that are certainly not stabilized. Contemporary biogeographic isolations result from increasing landscape fragmentation associated with human population expansions, and attempts to compensate caused by new population mixes. Regardless of how recently and quickly differences developed between the 6 operational taxonomic units described here, they are (1) anatomically definable, (2) statistically predictable over geographically and temporally broad samples, (3) have genetic components (not just ontogenetic and phenotypic), and (4) to these extents, are defendable. Thus it is possible to first conclude the existing taxonomy of North American wapiti is not based on natural biogeographic variation, and second, there are predictable differences between contiguous regions in which the populations are presently considered monotypic. This needs detailed analysis and correction, the relationships of the populations needs verification, and the taxonomy needs redefinition.

Resolving the phylogenetic relationships and intraspecific pedigrees of Cervus populations is important to systematics, ecology and especially conservation. How wapiti and red deer have responded to the last several glacial expansions and retreats has not been addressed. Comparative ecological studies have depended on an obsolete taxonomy that makes undefended assumptions on the homogeneity 
or heterogeneity of populations and irrelevance of sexual dimorphism. Successful conservation of wapiti depends on effective landscape planning and management, including uses of parks and reserves. Because of the species' history of long-distance movements and migrations managers of reserves usually counteract isolation by reducing, restoring and dispersing populations (Houston et al. 1990, Schonewald-Cox and Bayless 1986). Managers could avoid many problems that complicate their work unnecessarily, such as misguided legislation, misplaced restoration programs, and distrust of scientists (Buechner et al. 1992, Schonewald-Cox 1994), if the phylogeographic work precedes, rather than follows, legislation and management efforts.

Acknowledgements: The author wishes to thank the U.S. National Park Service, specifically Drs R. Briceland, J. Dennis and S. Veirs, Jr. Special thanks go to J. Bayless and J. Schonewald for assistance in conducting the early stages of this work, also to S. Blume and J. Smith for later contributions. Drs P. Dratch, V. Geist, S. Smallwood, D. VanVuren and anonymous referees were especially helpful with their advice. The author, now with U.S. National Biological Survey, takes sole responsibility for statements made herein,

\section{References}

Ahlen I. 1965. Studies on the red deer, Cervus elaphus L., in Scandinavia (taxonomy and osteology of prehistoric and recent populations). Viltrevy, Swedish Wildlife 3: 90-176.

Avise J. C. 1989. Gene trees and organismal histories: A phylogenetic approach to population biology. Evolution 43: 1192-1208.

Avise J. C., Ankney C. D. and Nelson W. S. 1990. Mitochondrial gene trees and the evolutionary relationship of mallard and black ducks. Evolution 44: 1109-1119.

Baccus R., Ryman N., Smith M. H., Reuterwall C. and Cameron D. 1983. Genetic variability and differentiation of large grazing mammals. J. Mammal. 64: 109-120.

Batcheler C. L. and McLennan M. J. 1977. Craniometric study of allometry adaptation and hybridism of red deer (Cervus elaphus scotticus, L) and wapiti (C. e. nelsoni, Bailey) in Fiordland, New Zealand. N. Z. Ecol. Soc. Proc. 24: 55-75.

Bailey V. 1935. A new name for the Rocky Mountain elk. Proc. Biol. Soc. Washington 48: 187-190.

Bryant L. D. and Maser C. 1982. Classification and distribution. [In: Elk of North America. J. W. Thomas and D. E. Toweill, eds]. Stackpole Books, Harrisburg, Pennsylvania: 1-59.

Bubenik A. B. 1982. Physiology. [In: Elk of North America. J. W. Thomas and D. E. Toweill, eds]. Stackpole Books, Harrisburg, Pennsylvania: 125-179.

Buechner M., Schonewald-Cox C., Sauvajot R. and Wilcox B. A. 1992. Cross-boundary issues for national Parks: what works "on the ground"? Environ. Manage. 16: 799-809.

Bureau of Land Management. 1986. The tule elk in California. 8th Annual Report to Congress.

Cameron A. G. and Vyse E. R. 1978. Heterozygosity in Yellowstone Park elk, Cervus canadensis. Biochem. Genet. 16: 651-657.

Caughley G. 1971. An investigation of hybridization between free ranging wapiti and red deer in New Zealand. New Zealand J. Sci. 144: 993-1008.

Dolan J. M., Jr 1988. A deer of many lands: A guide to the subspecies of the red deer Cervus elaphus L. Zoonooz 62: 4-34.

Dratch P. A. 1983. Genetic subdivision in Scottish red deer and North American wapiti. Unpubl. Ph. D. thesis, Univ. Edinburgh, Scotland: 1-151.

Dratch P. A. 1986. A marker for red deer-wapiti hybrids. Proc. New Zealand Soc. Anim. Production 46: $179-182$. 
Dratch P. A. and Gyllensten U. 1985. Genetic differentiation of red deer and North American elk (wapiti), Royal Soc. New Zealand, Bull. 22: 37-40.

Geist V. 1991. Elk Country. NorthWord Press Inc., Minocqua, Wisconsin, U.S.: 1-175.

Guthrie R. D. 1966. The extinct wapiti of Alaska and Yukon Territory. Can. J. Zool. 44: 47-57.

Gyllensten U., Ryman N., Reuterwall C. and Dratch P. 1983. Genetic differentiation in four Eurpean subspecies of red deer (Cervus elaphus L.). Heredity 5: 561-580.

Houston D. B., Schreiner E. G. and Moorhead B. B. 1990. Elk in Olympic National Park: will they persist over time? Natural Areas Journal 10: 6-11.

Houston D. B. 1982. The northern Yellowstone elk: Ecology and management. MacMillan Publ Co., New York: $1-474$

Hutton D. A. 1972. Variation in the skulls and antlers of wapiti (Cervus elaphus nelsoni Bailey). M. S. thesis, Univ. Calgary, Calgary, Alberta, Canada: 1-139.

Kucera J. F. 1991. Genetic variability in tule elk. Calif. Fish and Game 77: 70-78.

Lowe V. P. W. and Gardiner A. S. 1974. A re-examination of the subspecies of red deer (Crvus elaphus) with particular reference to the stocks in Britain. J. Zool., Lond. 174: 185-201.

Lowe V. P. W. and Gardiner A. S. 1989. Are the New and Old World wapitis (Cervus canadensis) conspecific with red deer (Cervus elaphus)? J. Zool, Lond. 218: 51-58.

Mayr E. 1988. Toward a new philosophy of biology: Observations of an evolutionist. Harvard University Press, Cambridge, Masssachusetts: 1-564.

Mayr E., Linsley E. G. and Usinger, R. L. 1953. Methods and principles of systematic zodogy. McGraw-Hill, New York: 1-328.

McCorquodale S. M., Eberhardt L. E. and Sargeant G. A. 1989. Antler characteristics in a colonzing elk population. J. Wildl. Manage. 53: 618-621.

McCullough D. R. 1969. The tule elk: Its history, behavior, and ecology. Univ, of California Publ.Zool. Univ. California Press, Berkeley and Los Angeles 88: 1-209.

Merriam C. H. 1897. Cervus roosevelti, a new elk from the Olympics. Proc. Biol. Soc. Washingtor 11: 271-275.

Merriam C. H. 1905. A new elk from California, Cervus nannodes. Proc. Biol. Soc. Washingtor 18: 23-26.

Nei M. 1972. Genetic distance between populations. Am. Nat. 106: 283-292.

Nelson E. W. 1902. A new species of elk from Arizona. Bull. American Museum of Natural History 6: $1-12$.

O'Brien S. J. and Mayr E. 1991. Bureaucratic mischief: Recognizing endangered species and subspecies. Science 251: 1187-1188.

SAS Institute, Inc. 1988. SAS/STAT User's Guide, release 6.03, Cary, NC.

Schonewald-Cox C., Chambers S. M., MacBryde B. and Thomas W. L. 1983. Genetics and Coiservation. Benjamin/Cummings, Inc. London: 1-722.

Schonewald-Cox C. M., Bayless J. W. and Schonewald J. 1985. Cranial morphometry of Pacific oast elk (Cervus elaphus). J. Mammal. 66: 63-74.

Schonewald-Cox C. M. and Bayless J. W. 1986. The boundary model: a geographical analysis of deign and conservation of nature reserves. Biol. Conserv. 38: 305-322.

Schonewald-Cox C. 1994. Protection of biological diversity: missing connection between science and management. [In: Biological diversity: Problems and challenges. S. K. Majumdar, F. J. Brenne, J. E. Lovich, J. F. Shalles and E. W. Miller, eds]. The Pennsylvania Academy of Science, Easton PA: $170-183$.

Received 6 November 1993, revised 12 September 1994, accepted 15 September 1994. 